\title{
SPACE AND MORALITY IN TOKELAU ${ }^{1}$
}

\author{
Ingjerd Hoëm
}

\section{Introduction}

What conceptualisations of space can be found in an atoll environment where the world consists of a very narrow band of land - the islets laying like a string of pearls surrounding a lagoon and with the vast ocean on all sides?

In Tokelau there are conceptualisations of space relating to areas of specialisation such as fishing and navigation, i.e. charts of wind directions, position of the stars, movements and seasons of fish and so on. These areas of knowledge have been documented elsewhere ${ }^{2}$, and will not be my particular concern here. I want to throw light on some basic principles of orientation in Tokelau, particularly as they relate to everyday life and carry moral implications.

The linguistic and cultural dimensions in Tokelau are intimately connected, and the overlaps between the two are many and varied. Through describing some aspects of how linguistic and moral conceptions of space enter into everyday life and become entwined through social practice, I wish to draw attention to some of the characteristics of this overlap.

Conceptions of space reflected in the grammar and lexicon of the language, as exemplified by demonstratives, directional particles, prepositions and local nouns, and how these relate to the culturally defined moral space within which people interact, will thus be the focus of my discussion.

\subsection{Knowledge and conceptualisation}

The Tokelau way of life, faka-Tokelau, reflects on the one hand an adaptation to the harsh realities of an atoll environment, and on the other hand the more recent adaptation to introduced institutions such as Christianity (since the $1860 \mathrm{~s}$ ), modern bureaucracy and the beginnings of a market economy (both in full from the early sixties). The kinship system is cognatic, and the daily round of activities is still very much centred around communal activities. A high value is placed on cooperation and sharing, and a demeanour which supports these values is praised accordingly.

\footnotetext{
${ }^{1}$ An earlier version of this paper was presented in May (1992) at the Cognitive Anthropology Research Group, Max Planck Institute for Psycholinguistics, and this article has benefited greatly from comments received at that time. I would also like to thank Prof. E. Hovdhaugen, Research Fellow A.M. Vonen and Director of Public Works, Matulino losefo, for very valuable comments.

${ }^{2}$ Cf. e.g. G. Macgregor (1937), J. Huntsman (1969), and Hooper and Huntsman (eds.) (1990) and (1991).
} 
In contrast to this stress on sharing, knowledge is traditionally considered to be family property. There is no kind of indigenous knowledge which can truly be said to be socially neutral. ${ }^{3}$ In this society, to possess knowledge and to be considered a knowledgeable person is intimately tied to age. To become a socially respected person is a life-long project, and those who are considered wise are more often than not above 70 .

Knowledge in this sense pertains mainly to the areas of genealogical relations, of navigation techniques and the position of the stars, of old songs, chants and spells, and it is ultimately connected to land, fenua. By saying that such knowledge is ultimately connected to land, I mean on the one hand that family members are tied together on the basis of common ownership of particular land areas and that familiarity with the genealogical links which validate this relationship between people and land is perhaps the most important knowledge one can possess.

On the other hand, what I have just said can be considered an aspect of a more general tendency to ground historical knowledge in the natural environment. In fact every tiny area of sand, coral-stones, reef and so on, is named and has a story and often a song connected to it as well. ${ }^{4}$

The traditional areas of specialisation, relating to knowledge about the environment such as navigation, are not as important as they used to be. This is mainly because of changes in the technology used, such as the introduction of outboard motors. To a certain extent these developments have been accompanied by a new perception of traditional knowledge as being the Tokelau culture, which must be preserved lest it be lost. In spite of this development however, the possession of such knowledge and skills is still very much the basis for the existing social differentiation and retains its importance when it comes to regulating use and ownership of land and running the day-to-day affairs of the villages.

When looking at patterns of communication in Tokelau with a focus on basic categories of orientation, I find a tendency to conceptualise social relationships in concrete spatial terms.

To illustrate this tendency, I shall describe how culturally important knowledge is displayed, becomes defined and redefined through competitive festive activities which take place through an institution which in the native terminology is called the 'sides' ${ }^{5}$ (or moieties), faitu, of the villages. The social institution of these sides provides an arena for the expression and negotiation of Tokelau values. The cardinal points of Tokelau existence are given an aesthetic form, which, by integrating the personal and the communal, serves to define an individual as a Tokelauan, and in this way, the environmental, kinesthetic and linguistic dimensions of space become integrated in the moral universe.

${ }^{3}$ Different attitudes towards knowledge are being promoted through the school-system. For descriptions of this see Hoëm (1990) and V. Sallen (1983).

${ }^{4}$ This is true of many traditional small-scale societies, e.g. many of the island groups of the Pacific. (Cf. e.g. R. Firth's material from Tikopia.)

5 In Hooper and Huntsman's terminology, moieties. Cf. e.g. Huntsman (1971). 


\subsection{Tokelau; a general background}

Today Tokelau comprises three atolls; Atafu being the northern, Nukunonu the middle, and Fakaofo the southernmost. Originally there were four atolls, but the fourth, Olohenga or Swain's Island is now politically a part of American Samoa. The islands are situated about $500 \mathrm{~km}$. north of Western Samoa, close to the Equator. Each atoll consists of hundreds of small islets connected by coral reef and surrounding a lagoon. There are no deep water passes into the lagoon and therefore ships must stand off, while cargo and passengers are taken ashore in smaller boats.

Communication between the islands and with the outside world is at present maintained by a ship transporting both freight and passengers, which sails to and from Samoa approximately ten times a year, and by the Tutolu, an inter-atoll vessel.

The land area is altogether between 10 and 12 square kilometres depending on how the distinction between rocks and land is made. None of the islets rise more than 5 feet above sea level. There is very little fertile soil, and the annual rainfall is irregular. In contrast, the sea area belonging to Tokelau is large, about 290,000 sq. km., and is abundant in fish. On each of the three atolls, the population is concentrated on one islet on the western, leeward side of the atoll. ${ }^{6}$ This means that a population of about 1500 people live on approximately 2-3 square kilometres altogether.

In 1982 the total number of people living in Tokelau was approximately 1650 , and it is about the same today. Due to over-population on the islands, a government sponsored migration scheme to New Zealand was started in the mid-1960's, and there are now about 4-5000 Tokelauans living more or less permanently in New Zealand.

There were sporadic contacts between the indigenous people of Tokelau and Westerners during the late 18th and early 19th centuries. Missionary activity, both Catholic and Protestant, commenced in the early 1860 s. In 1863 a major blow to the people of Tokelau came as all the atolls were raided by slavers engaged in the Peruvian slave trade. They removed more than 45 percent of the population, mainly the able-bodied men. Tokelau was declared a protectorate of Great Britain in 1889, incorporated into the Gilbert and Ellice Island Protectorate in 1910, and later, in 1916, into the Gilbert and Ellice Islands colony. Disannexed in 1924, the islands came under the effective control of the New Zealand Administration of Western Samoa in 1925.

Until the 1950 s the contact with New Zealand was restricted to short term visits by officials, and Tokelau was largely left to itself. Western Samoa became independent in 1962, and in 1964 Tokelau was given the choice of becoming affiliated with either Western Samoa or the Cook Islands. In response to this Tokelau asked to be allowed to continue their association with New Zealand. In terms of U.N. classification, Tokelau is today a non self-governing territory, but is moving towards taking over the responsibility for its own government and administration.

The mother-tongue is the Tokelau language which belongs to the Polynesian branch of the Austronesian language family. Linguistically classified as belonging to

${ }^{6}$ On Fakaofo, the population now lives on two islets, Fale and Fenuafala. 
the Samoic Outlier Subgroup of Polynesian it is closely related to the languages of its neighbouring countries, Tuvalu and Samoa, to the languages of its Polynesian speaking island neighbours in the east, Northern Cook Islands (i.e. Pukapuka, Manihiki and Rakahanga), and to the languages of the so-called Polynesian Outliers in the west, Sikaiana and Luangiua (Solomon Islands).

\subsection{Social organisation}

All members of each village either have rights to land on the island or else are married to someone who does. Land is inalienable property in the sense that it is forbidden to sell land by law. The village councils consist of male elders and constitute together with the General Fono (assembly on the national level) the political leadership. The kaiga or extended families are the major property-holding units in Tokelau. A kin group in the sense of "clan" is seen as founded by a couple and as being structurally held together by siblings, i.e. a brother and a sister: Tamatane is loosely speaking the "male" side, i.e. the brother's sons and their offspring (meaning that also women can occupy this position); tamafafine is the "female" side, i.e. the sister's daughters and their offspring (meaning that also men can occupy this position). Status as tamatane and tamafafine usually determines the allocation of leadership positions and of rights and obligations among members. The tamatane have power and authority over productive property and its use, i.e. right to control land. Tamafafine have the right to live on the land and to control and distribute the produce of cooperative enterprises and other property associated with the kaiga. The members of a kaiga exploit these lands jointly. These estates were in principle broken up approximately every fourth generation, as a result of strict rules against marrying closer than third or ideally fourth cousins: Since people who hold land in common are per definition counted as kinsmen, and the cognatic kinship system implies that everybody has kinship relations, however distant, to everybody else - this dilemma is solved by dividing up land areas when distantly related cousins marry.

Since the abolishment of the chiefly lines, the traditional hierarchy, which held the clans close together and largely prevented this splitting up of estates, has lost much of its power, and since then this splitting up tendency has increased markedly. I shall return to this point in my discussion of how the institution of 'sides' in the villages helps to balance the political and personal conflicts, which this tendency to fractioning very often leads to. Life in an atoll environment such as this is coupled with an egalitarian ideology and a communal orientation which encourage the creation of crosscutting networks, of a multitude of task-oriented groups, and of various, often conflicting obligations.

Through everyday life, as epitomised in the institution of the 'sides' or faitu, the personal and the collective dimensions are merged and a particular orientation, which encompasses the natural, physical, and social environment is reinforced. 


\section{Symbolic aspects of space}

To understand how this particular orientation is brought about we shall have to consider how the natural environment of the atolls is conceptualised, how this spatial orientation is encoded linguistically, and finally how the linguistic and the socio-cultural dimensions interact.

\subsection{Spatial orientation and the natural environment ${ }^{7}$}

The orientation of interest and activity in the Tokelau village is centripetal, toward the lagoon, rather than centrifugal, toward the ocean and the world beyond. The immediate world consists of a very narrow band of land, centred around the lagoon, and people who leave the villages to go abroad are metaphorically and socially dead. (At least until they come back again).

The lagoon side is seen as the front of the village, whereas the ocean lies at its back. The distinction which is made between the socially controlled and moral areas, the villages, $n u k u$, and the so-called bush areas, vao, which include everything on the main island which is not village, not directly under social control, may be seen as a symbolic elaboration of a spatial contrast between 'frontness' and 'backness'. It is in the back, in the bush, that danger lurks, where one is vulnerable to attacks by aitu, spirits or ghosts. This is in agreement with B. Shore's description of the symbolic organisation of villages in Samoa as well, in spite of the very different landscape one finds there, with the ocean on one side of the villages and the forest and mountains on the other.

The noun moana refers to the open ocean. The lagoon is called namo, and as a locative noun it means the lagoon side of the village.

Spatial orientation as seen from the village is basically as follows: The locative noun gatai $i^{8}$ denotes direction towards the lagoon. The locative noun gauta, from $g a$ - and uta meaning the islets on the far side of the lagoon, denotes 'towards land', 'on land' or 'further inland'. The islets on the far side of the lagoon where the coconut plantations are, are called uta. That is, the areas which the council of elders traditionally control access to.

The lagoon side of the village is commonly referred to as gatai, the open ocean side as $i$ tua., and any direction further inland, i.e. away from the shore, as gauta.

In the Tokelau Dictionary, one finds gatai and gauta defined more generally. There gatai is described as referring to sea and shore as seen from the land, while gauta refers to shore and land as seen from the sea. I find this definition slightly problematic however, since it is not common that people refer to the open ocean side of the village as gatai, only as $i$ tua.

\footnotetext{
${ }^{7}$ I am indebted to Matulino Iosefo for checking the linguistic information presented in this section.

${ }^{8} \mathrm{Ga}$ - is what Mosel and Hovdhaugen in their Samoan Reference Grammar call a relict prefix, archaic with unknown meaning, tai means sea.
} 


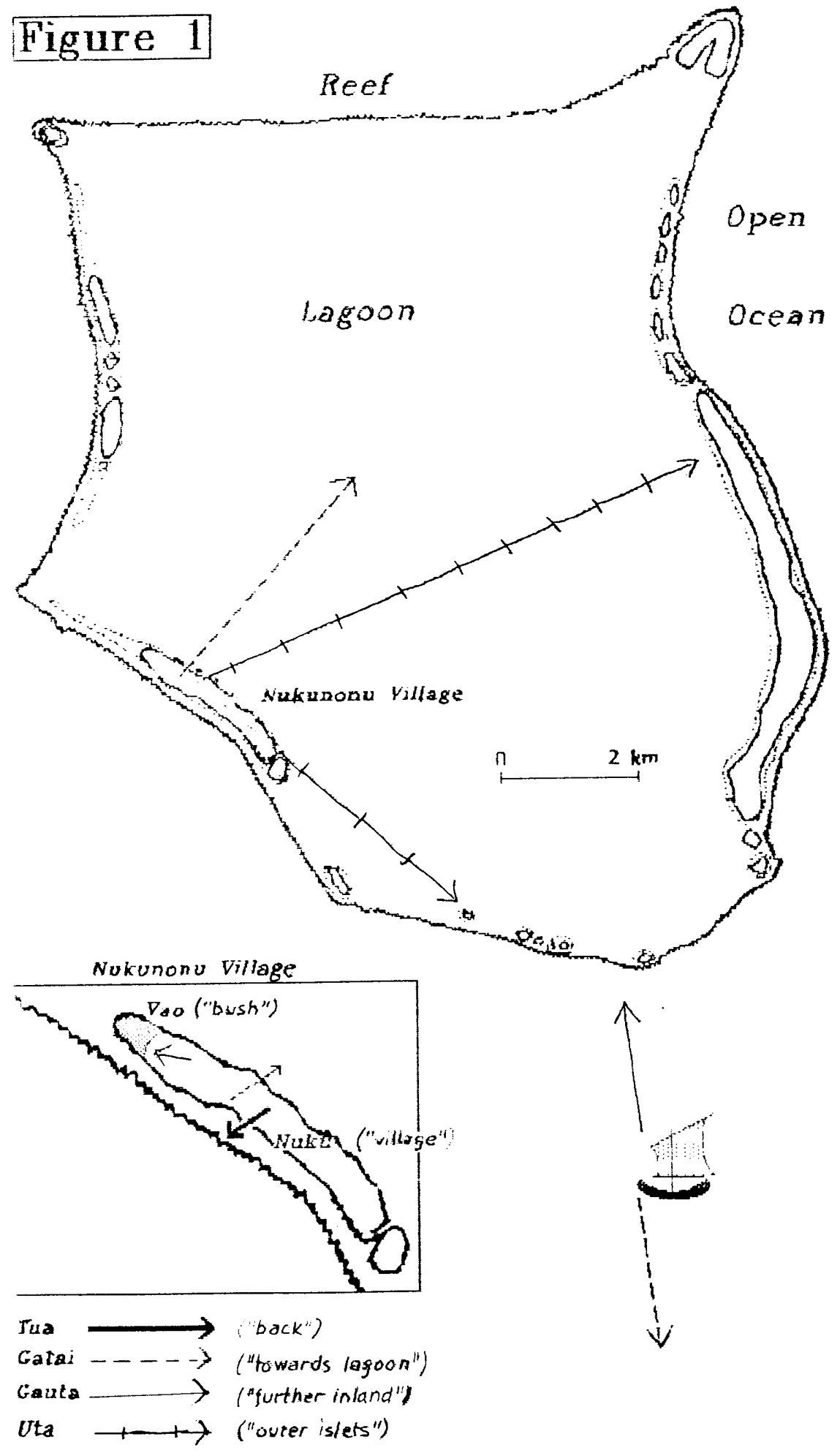


I believe that the problem is that the English word 'sea', in fact can refer to two different things, the lagoon and the open ocean, and that the terms gatai and gauta have different denotations according to the context of usage. If one is out on the open ocean fishing, gatai is used about 'further out towards the ocean' and gauta about 'towards land'. Figure 1, Spatial Orientation, is an illustration of how these terms gains different semantic contents according to where they are used, whether in the village or out on the ocean.

\subsection{Spatial orientation and the moral universe}

The moral universe, in particular as it relates to notions of personhood has, as I see it, a bias towards being conceptually grounded in the natural environment. This is also realised in kinesthetics. I shall illustrate this point by demonstrating how the above-mentioned notions of 'frontness' and 'backness' are related to what may be called a person's social 'face'.

The term, i tua or i tuafenua, denoting direction towards the open ocean side is used in contrast with the term gatai, denoting lagoon side. The term $i$ tua carries the additional meaning 'in the back'. As implied by the above discussion, these terms carry moral connotations as well.

Children and young people are seen as incomplete human beings who gradually acquire the strength, but still lack the necessary knowledge and power of judgement to be able to take care of themselves. As a person grows older, he or she gradually gains more knowledge and is accordingly vested with more power of judgement (over others). This process is theoretically one of endless refinement, until, if health allows, one (as a man) approaches the position of absolute elder. It is this belief which lends the elders their power. The elders have the power to regulate the activities in the village, such as imposing evening curfews and so on. The controlled, dignified, and above all, quiet, behaviour associated with the village areas is quite different from what may happen in the uncontrolled, wild areas in the back.

A native designation of 'speech out of place' is hopotulaga, to 'speak or do things which are out of one's area of control or authority, to presume as though one has the authority' (lit. hopo, 'go over the boundary', tulaga, 'position'). It is considered very unseemly to speak to someone, especially one older than oneself, from a physically higher position. This is expressed for instance in the word talitu meaning 'to answer back while one is standing' (i.e. bad manners). This marked concern with the body's position in social space is shown for instance in the practice of bowing down and saying tulou if one has to pass in front of a person.

Traditionally a woman's place is in the home, that is, inside or close to the house, where she is supposed to stay put, nofo, (sit, dwell), whereas a man is supposed to be on the road, that is, going out, carrying out his activities of fishing, plantation tending etc. ${ }^{9}$ As women spend most of their time in the villages, they

\footnotetext{
${ }^{9}$ See for instance Huntsman and Hooper who write: "There is a widely known Tokelauan adage - ko te fafine e nofo: ko tagata e fano it te auala. 'The woman stays: the man goes on the path' which expresses a basic principle of Tokelau thought, and which is used by Tokelauans, quite explicitly, to
} 
have the opportunity to keep a keen eye on what is going on, everybody's comings and goings are constantly checked by means of phatic talk exchanges such as "ko koe ka fano ki fea?" ('Where are you going'?), answer: "Ko au ka fano ki ..." ('I am going to...'), and "sanctioned" by a reply "Io, fano la" ('Yes, go then', polite form). Such and similar verbal exchanges generally take place every time people meet throughout the day, and naturally this is often more a matter of politeness than of conveying any real information, but it also demonstrates the right everybody has to know what a person is up to. ${ }^{10}$

Etiquette related to verbal (and other) interaction between males and females is closely tied up with the concept of kinship. There are basically two different categories of people in Tokelauan society, kinsmen and non-kinsmen. The members of the latter category consist broadly, as a rule of thumb, of those people who do not hold land in common. These are the potential marriage partners.

Both as a moral dictum and as a practical consequence of the traditional division of labour, contact with members of the opposite sex is ordinarily kept at a minimum. However, this has always been a question of degree, if only because there are no thick walls behind which to seclude the female part of the population, and also because the size of the islands forbids a total spatial separation of the work spheres. The pattern defining proper behaviour between males and females, and between man and wife in public situations, is still very much the same as it has been since the advent of Christianity. The members of the opposite sex with whom one interacts are largely members of one's own family. As such, the proper role-behaviour is modelled on the brother-sister relationship, whose affective pattern is based on avoidance. A good girl is still one who stays in the house, except when ordered to take part in communal work, and who spends her time looking after the needs of her family, weaving, cooking, washing and cleaning etc. The males are, most of the time, occupied with outdoor activities such as village work, fishing etc.

The majority of women state that a girl should not talk to men, and especially not to married men. It is shameful for a woman to be too forward in her dealings with the opposite sex, and if "something happens", the middle-aged and older women usually agree that the fault lies with the girl. To be matamuli, i.e. 'shy, reserved', (lit. 'face, last or back'), is considered to be very positive, whereas if a girl is labelled as matamua, i.e. 'forward' and 'direct', (lit. 'face, forward or first') this arouses horror, disgust and, ... a certain fascination.

point up the rationale for various diverse customs and aspects of Tokelau life. In general, female activity is on land, within the village and in the domestic sphere of house and cook-house, while male activity is at sea, on the outlying plantation islets of the atoll and in the public places of the village, known figuratively as 'the path'. Thus land and sea, village and outlying islets, domestic and public arenas of the village are contrasted as complementary domains of the sexes. In each contrast set, it is the female who is more confined, more restricted in both social and spacial terms." And they conclude: "In short, a man's life is outside and active while a woman's life is inside and largely sedentary" (1975: 418).

${ }^{10}$ As I say, this practice is sometimes quite simply a conversational routine. Even so, it is a social fact in Tokelau that fellow villagers indeed have a right to know what others are up to, and that such phatic talk exchanges very frequently is employed to exercise this right. For other illustrations of this point see G. Senft's discussions in relation to the concept of 'ritual communication', Senft (1987) and (1991). 
The women have the power of keeping scores on personal appearance and standards of cleanliness, i.e. of a person's performance in public in general, and if one fails to meet the standards of acceptability their reaction will be immediate. The spilling over of the private into the public sphere is a matter of shame, $m a$, and a breach, deviation, mistake or mess-up. The talks and comments are centred around similar values as those observed by Levy as being central for Tahitians. "Casualness and clean and fragrantly presented surfaces"11, a smiling face and an outgoing, light-hearted, sharing (i.e. collective-oriented, not ego-oriented) attitude is highly praised in Tokelauan society.

\subsection{Context dependency}

We shall now move on to consider the linguistic dimension of conceptualisations of space as it overlaps with the socio-cultural dimension.

Tokelauan is said to show a great degree of so-called context-dependency. Both "Samoan" 12 and Tokelauan are described as discourse-oriented languages where contextual information is very important in the coding and decoding of linguistic forms," or 'cool' languages according to John R. Ross's term as it is used in Huang $1984 .{ }^{13}$ Huang describes a 'cool' medium as a medium which "depends upon considerable participation by the hearer". Huang follows Ross in suggesting the possibility of "classifying languages on the basis of the explicitness with which they express certain anaphoric elements." Within the framework proposed by Huang, discourse-oriented languages are opposed to what he calls sentence-dependent languages.

As will become clear from my discussion, I have certain reservations with respect to the use of this dichotomy, as it easily leads us to assume that the sentence-dependent languages carry the information necessary for the decoding of the sentence linguistically and that the discourse-oriented languages do not. Huang's statement that a discourse-oriented language "depends upon considerable participation from the hearer", may easily lead us to assume that the understanding of a sentence-dependent language requires no such effort.

In Tokelau speeches and story-telling, a certain kind of sentence construction is even more noticeable than in everyday speech. Robin Hooper (1987) calls this narrative structure 'informative presupposition'. She bases her argument on a distinction between 'given' and 'known' information. She describes this speech type as containing "a focussed constituent which is largely anaphoric in its relation to the preceding discourse. The presupposition contains new information which is presented as known" (1987: 20). And she rightly observes how "this construction lends itself to a variety of rhetorical purposes".

\footnotetext{
${ }^{11}$ Levy (1973: 361).
}

${ }^{12}$ For an illustration of this aspect in Samoan, see U. Mosel and E. Hovdhaugen (1992, Ch.9.5.) "The grammatical dispensability of arguments".

${ }^{13}$ Vonen (1988: 2). 
This could be taken as an illustration of Tokelauan being 'context-dependent', that is, dependent on the speech situation. The term 'discourse-oriented' could then be reserved for sentences of the following kind (taken from a fishing story): "Hoko te tahi uka. Fano. Fano. Fano. Fano": "Join a line. Go. Go. Go. Go." I.e. sentences needing a reference forward or backward to other utterances/sentences. But this still leaves us with the question of the usefulness of the concept of context dependency and precisely what this concept should be taken to imply.

In spite of the very frequent omission of pronouns in narratives, so-called contextual information can be gleaned from the system of demonstrative particles, which together with the directional particles makes it possible to convey very precise information about the relative spatial position of the characters in a narrative or the participants in a conversation vis-a-vis each other.

We shall now briefly look at some of the means by which such relationships are conveyed. In addition to the prepositions $i$, 'in, at, with, because of, from', which indicates location in space, and $k i$, which indicates direction towards a goal, i.e. movement, there are four so-called directional particles which are very common. These indicate the direction in which the action of the verb is performed, and this basic idea of direction is also extended metaphorically in a number of ways.

The first of these directional particles is mai, which indicates something that happens in the direction of or towards the position of the speaker or the central person of the narrative; words, emotions or behaviour directed towards the speaker; processes in which the speaker has an interest or by which he may be affected.

The second is atu, which signifies motion away from the speaker or the central person of the narrative; words, emotions or behaviour directed towards others/the person spoken to; and interestingly, the greater element in a comparison; or any outward-looking experience. That atu and not mai should be given this function is consistent with what we learned about Tokelauan self-abasement.

The third directional particle is ifo which indicates motion downwards or towards the sea. It has the additional moral connotations of submission, or condescension from a person of higher status to someone of lower status, etc. Finally, the fourth is ake which indicates motion upwards or in an inland direction.

These directional particles or directionals allow one to omit the pronoun and it is particularly common to use mai in this way (in the place of $a u$, i.e. first person singular personal pronoun), as in the following sentences:

"Lea mai" "Tell me!" (Lit. "Tell, in this direction"), "Fakatali mai koe" "Wait for me, you!" (Lit. "Wait, in this direction, you"), or Na tautala mai te toeaina" "The elder said to me" (Lit. "Said, in this direction, the elder") ${ }^{14}$.

To omit the first person personal pronoun, or rather to replace it with the directional mai is a very common thing to do in Tokelau narratives. The general tendency is to drop the pronouns in favour of directional and demonstrative particles. The main characters of a narrative are very often not referred to in a direct fashion. This is morally proper as it allows for a downplay of personal involvement and thus lends a sense of greater personal distance to the narrative.

${ }^{14}$ These examples are taken from E. Hovdhaugen, I. Hoëm, C.M. Iosefo, and A.M. Vonen (1990) 
Thus I would relate the prevalence of such directionals and demonstratives to the fact that they serve as "pointers" to spatial relations between the characters in the narratives.

In addition to the directionals denoting movement, Tokelauan has two demonstrative particles, 'te' 'this, that', 'ie' 'these, those', which are frequently combined with the following particles, which indicate position in relation to the participants in a conversation, that is, their location.

-nei (near the speaker)

-na (near the person spoken to)

- $i a$ (away from both speaker and hearer).

$T e$ and $i e$ are used without the position particles when there is no possibility of misunderstanding, as when the precise meaning can be conveyed by a gesture or glance. The demonstratives are also used to refer back to something that has been mentioned earlier, especially in story-telling. This, combined with a system of pronominals which has both exclusive and inclusive dual and (1rst. pers.) plural are means by which social space can be defined in great detail.

In this context, it is interesting to interpret the so-called 'context dependency' and 'discourse orientation' also as an expression of moral concerns related to the social face. This interpretation is supported by the observation that spatial relationships, both between the characters of a narrative, and with regards to situating a narrative in the natural environment, are clearly marked and expressed in narratives.

I believe that it is a mistake to interpret the lack of pronouns e.g. in narratives as an omission of information. The information is not omitted; it is differently coded linguistically. Relationships between persons are represented as spatial relationships indicating movement and location.

\subsection{Context orientation}

As I have already mentioned, many studies of various Polynesian societies stress the amount of energy put into the face work ${ }^{15}$ involved in the presentation of the "prototypical South Seas Islander," with 'fragrant', 'polished surfaces' and a smiling, light hearted, outgoing attitude. ${ }^{16}$ These cultures have also been described as having a performative cast. In the same vein B. Shore has described Samoa as a "shame" culture, as opposed to a "guilt" culture that fosters an internalised conscience, which he considers a product of the Western culture. He opposes the Western ideal of an integrated personality with a constant moral existence independent of contexts, with what he labels the context orientation of Samoan morality. It is interesting to note how anthropologists, I believe quite independently of the linguists who have described Samoan and Tokelauan as context dependent languages, describe the Samoan culture as context oriented. I suspect that what lies

\footnotetext{
${ }^{15}$ I use this concept in a Goffmanian sense.

${ }^{16}$ See for an illustration of this the work of Levy from Tahati.
} 
behind this somewhat vague designation of 'context orientation', is a highly developed sense of the art of communication among the Samoans and Tokelauans.

Indigenous ideas of truth (a parallel can be found to Besnier's descriptions from the atoll Nukulaelae in Tuvalu, which is linguistically and culturally closely related to Tokelau) are connected with the concept of katoa, 'wholeness', 'fullness', or 'richness of detail'. This whole, when it comes to notions of social personhood, comprises all the 'sides', itu, of which a person consists. An interesting point in this connection is J. Huntsman's (1971: 320) remark that: "A word derived from kaiga, itukaiga (itu means side or portion) is used to classify, sort or type animals, plants, objects or activities. The myriad varieties of fish are classified into a number of overlapping itukaiga by their appearance, habitat and behaviour etc. Both the derived word and the base word denote two or more items which share distinctive attributes."

We see here that the concept of 'sides', itu is employed as the principle by which things are relegated into categories, and that it seems to be the ideational basis for the classificatory system as a whole.

Men are collectively called the itu malohi or strong side, whereas the women are the itu vaivai or weak side, and the same is the case of the tama tane:tama fafine divisions ${ }^{17}$ A person's characteristics or uiga, are seen as qualities inherent in a person's relationships. In other words, it is the relationships which are seen as constitutive of a person, rather than, as in Western culture, the obverse.

Even though I consider such dichotomies (i.e. Samoan and Tokelauan culture as context oriented versus Western cultures as context independent), as simplifying things to the point of distortion, it is certainly true that people on Tokelau, as well as on Samoa, do put great stress on relationships - and that they value and foster an awareness of situations.

The concept of 'sides', itu, also has a spatial expression in the division of the villages into two halves which constitute opposing teams. The particular characteristic of this opposition is that this spatial division of the village into two parts is the only truly arbitrary division, as compared to the 'front:back', 'village:bush', 'lagoon:open ocean' distinctions. These all have in common a conceptual grounding in bodily and/or environmental space. The 'sides' have their conceptual grounding in social space only. This fact makes this construct unique in creating an arena which allows for the mediation of the moral aspects connected with the other oppositions.

In Tokelau, as I mentioned above, the social order is very complex, consisting of a number of groups with overlapping membership. This means that in most situations an individual has to make a choice between which rights and obligations $\mathrm{s} /$ he wishes to activate. There is one institution though, the faitu (which linguistically can be analysed as fai, itu, 'make sides'), which by dividing the village in two creates an arena which in principle overrides these divisions. We shall now see how this institution creates an arena which allows for an expression of the other divisions and mediation between them. ${ }^{18}$

${ }^{17}$ Cf. page 4.

18 For a discussion of a Pukapukan institution which seems to exhibit some parallel characteristics to the Tokelau faitu, cf. Borofsky (1987). 
Tokelauans tend to perceive the environment they inhabit as a socio-historical map. This is why, when Tokelau history was introduced into the school-curriculum, the teachers invited elders to come to the schools and teach the subject to the pupils. The elders responded to this by taking the children on what they called an "historical tour" around the atoll, during which the elders recounted the historical tales connected with each place they stopped at.

Most of the knowledge of environmental space that is connected with historical everits, is preserved in songs and presented in speeches held at public gatherings. It is important to note that this knowledge of the socio-historical map of the atolls is not morally neutral. There are for example a particular set of songs about each atoll and their particular treasures. ${ }^{19}$ At a certain period in history the three atolls were at war, and Fakaofo gained overlordship and attracted tribute from the other atolls. Many of the landmarks are related to the old order, as it was before the days of war, when the land areas belonging to each clan were more clearly demarcated and separate and before the atolls had become linked by ties of intermarriage. Other landmarks are associated with things that took place during the wars, and to bring up any of this knowledge is to threaten the present-day stability. The elders are entitled to handle this knowledge, for example in the case of land disputes, and it is also they who decide which aspects of social organisation should be activated at any time. This kind of knowledge is often displayed at 'side' related events, and may have political consequences.

Public gatherings, called fiafia (which means 'to be happy'), are an occasion for entertainment, for skits, speeches, and above all, dancing. Fiafia's are held at the close of inter-atoll meetings or at the end of communal cricket games (where "everybody" participates through their membership in one of the 'sides', faitu of the village. The 'sides' divide the village into two halves, with the dividing line going somewhere in the middle of the village, but this division is not merged with any other form of social differentiation. At times when the number of inhabitants on the islands was higher than today, it has apparently happened that the villages have been divided into three 'sides', parts or teams. Membership in the 'sides' is based primarily on parental affiliations, but individuals may change their affiliation at the time of marriage and according to residence. The 'sides' are mainly activated for competitive activities, e.g. games such as cricket and dancing, and they have their own appointed male leaders. Sometimes the 'sides' also undertake village work.

In earlier days Tokelau society had a wider range of institutions for the transmission and (re)creation of cultural knowledge, such as the ceremony held for a man entering the ranks of the tautai; or master fishermen, the kaukumete $^{20}$; which was held in the meeting house for all to see. Today, while many of these institutions, such as the kaukumete, and the practice of telling kakai;, folk tales, in the evenings at the meeting house, have been discontinued, part of their content and spirit have entered into and been merged with collective performances such as the fiafia.

19 I.e. Fakaofo has water, Nukunonu has kie-pandanus and Atafu has kanava tree, all highly valued resources. See Hooper and Huntsman $(1982,1990,1991)$.

${ }^{20}$ See Hooper and Huntsman (eds.) (1991: 177). 
The fiafia, through its assimilation of the art forms of different institutions, has become very important in the Tokelau society of today. Seen as part of a larger context, a fiafia is always the concluding event of a whole chain of activities. The preceding activities might be the village's two sides playing a cricket game, with preparation of food, skits, songs and decorations; a work project, such as thatching a roof, carried out in a spirit of competition between the sides, often over a span of days; or a meeting of the three atolls for a General Fono, in which case the wider context would be the political relations between the three atolls. Thus, the internal agenda and significance of the items created for or performed at the fiafia (for example, songs, speeches, skits) will vary according to the nature of the wider context of which the fiafia forms the concluding event. But one trait which all such performances have in common is the challenging, competitive spirit of the exchanges taking place, regardless of whether the participants are the sides of a village or whether it is an inter-atoll gathering. A fiafia is for everybody, and in this sense it is emblematic of the spirit of maopoopo; collective congregation and participation.

Huntsman describes the relationship between the sides in the following way: "The faitu are in unending competition; there is no ultimate winner nor finally vanquished. Competition focuses on cricket. Competitive spirit is present, if unstated, in any enterprise in which both faitu are engaged: composition and performance of songs and dances, labour projects, fish drives and annual feasts." She continues: "Each side jocularly mocks and taunts its opposite in skits and harangues. Cricket winners haze and humiliate cricket losers, who respond with stoic pride while plotting their come-back. Each side glories in and crows about its achievements, while criticising and belittling the other." She concludes by stating that "there is little respect, compassion and sympathy between these similar and competitive units. ${ }^{21 "}$ (1971: 325)

When seen against the background of the Tokelau egalitarian ethic, the value placed on modesty and meekness, and the negative reactions against self-aggrandisement, where one of the more positive statements one can make about another person is that she or he has "fano ki lalo," literally "gone down, below," that is "below oneself," this competitive spirit stands out markedly. When talking with people and observing the everyday affairs of the villages, a certain amount of competitiveness and hostility between the kau kaiga (groups of extended families) is noticeable. But it is equally apparent that even though this is an important motive underlying many events, it is an attitude which is overtly condemned, and which is certainly not publicly encouraged.

In contrast, the competitive, "self aggrandising" activities of the teams or sides are openly encouraged and celebrated. Clearly, the formalisation or ritualisation of these moiety-centred events might be seen as providing an outlet for messages which are normally suppressed, at least in formal public contexts. In everyday life there is a more or less continous interaction between different constellations of persons in different contexts. A fiafia might constitute a forum for the actualisation of many such different alignments at the same time. Within your team there might perhaps be small fractions or "cheer-gangs" which support individuals in their quest for

${ }^{21}$ Note her use of the word 'similar' here, i.e. those units classified as belonging to the same category. 
excellence in performance. In this way many considerations are made more or less simultaneously in the same event in these performances, even though the overt or overriding goal is to create a common consensus.

It is possible, analytically, to separate many "games" in such a fiafia. On the one hand, there is the immediate observable performance, where one relates to and works on the quest for excellence and which has the distinct character of spontaneous elaboration and improvisation. On the other hand, and more implicitly embedded in the competitively tinged performance, there exists a "deeper" play, which concerns the formulation, creation or invention of central paradigmatic traits of Tokelau culture. 22 The performance itself, in addition to the perspective mentioned above, may be perceived as a medium for externalising power relations. As the teams ideally are non-convergent with any real lines of conflict, their competition allows for the creation of a relatively neutral arena where meaning can be made the object of negotiations. ${ }^{23}$

\section{Conclusion}

We have seen how Tokelau people conceive of their historical heritage as being situated in the natural environment. Knowledge of "the order of things" is displayed and exercised among other things through competition between the sides, faitu, of the villages and between the three atolls. At the same time, the social institution of the sides provides an arena which also allows for a negotiation of Tokelau values. In this way life in Tokelau is given an aesthetic form which, by integrating the personal and the communal, the past and the present, serves to define Tokelau identity.

The duality in the institution of the sides is not based on kinship. As such it seems to provide a neutral arena serving to bridge the opposition between other fractions. It does not carry any associations to the symbolic oppositions of gender and power or centre versus periphery that are found in the social organisation of the villages. Precisely for this reason it constitutes an alternative, neutral arena for handling these oppositions which we have seen are intrinsic parts of village life.

The Tokelauans have created a universe, which has a very tight integration between moral, environmental, and physical or kinesthetic space, and which provides the individual with rather clear directions for navigation through social space. We have seen how, linguistically, the dimensions of movement or directionality and location are very central, and that persons and relations between persons tend to be represented as movement in space and as situated in space.

When examining the relationship between the linguistic and the socio-cultural dimensions, questions related to context come to the fore. Conceptualisations of space stand out as a particularly fruitful ground for untangling some of those

${ }^{22}$ Cf. Geertz' use of the concepts 'deep' and 'shallow' play (Geertz. 1973).

${ }^{23}$ An appreciation of this is shown in people's description of the Tokelauan practice of shifting (by rotating, geographically, the axis of the sides 45 degrees) side affiliations if the conflicts eventually gets too settled. 
questions. In Tokelau conceptualisations of space an important distinction is found between those concepts which are contextually grounded in bodily and/or environmental space and those which are contextually grounded in social space. An interesting point in this respect is that the tension between these concepts allows for a large amount of flexibility in the creation of Tokelau culture.

\section{References}

Besnier, N. (1988) The linguistic relationships of spoken and written nukulaclae registers. Language 64: 707-36.

Besnier, N. (1991) Literacy and the notion of person on nukulaelae atoll. American Anthropologist 93: $570-87$.

Borofsky, R. (1987) Making history: Pukapukan and anthropological constructions of knowledge. Cambridge: Cambridge University Press.

Firth, R. (1957) [1936] We, the Tikopia: A sociological study of kinship in primitive Polynesia. London: Allen and Unwin.

Firth and McLean (1990) Tikopia songs: Poetic and musical art of a Polynesian people of the Solomon Islands. Cambridge: Cambridge University Press.

Geertz, C. (1973) The interpretation of cultures. New York: Basic Books.

Goffman, E. (1959) The presentation of self in everyday life. New York: Doubleday-Anchor.

Hoëm. I. (1990) Sharing a langrage - sharing a way of life? Aspects of the relation between language, culture and society in Tokelau 1986-88. Unpublished Magister Artium dissertation in Social Anthropology, University of Oslo.

Hooper, A. and J. Huntsman (1972) The Tokelau Islands migration study: Behavioural studies. In J. Stanhope and J.S. Dodge (eds.), Migration and related social and health problems in New Zealand and the Pacific. Wellington: Epidemiology unit, Wellington Hospital.

Hooper, A. and J. Huntsman (1975) Male and female in Tokelau culture. Journal of the Polynesian Society 84: 415-30.

Hooper, A. and J. Huntsman (1985) Structures of Tokelau history. In A. Hooper and J. Huntsman (eds.), Transformations of Polynesian culture . Auckland: The Polynesian Society (Inc).

Hooper, A. and J. Huntsman (eds.) (1990 and 1991) Matagi Tokelau. History and traditions of Tokelau. Apia and Suva: Office for Tokelau Affairs and University of the South Pacific.

Hooper, R. (1987) The Discourse function of focus constructions in Tokelauan. Paper presented at the 7th New Zealand Linguistics Conference, Dunedin.

Hovdhaugen, E., I. Hocm, C.M. losefo, and A.M. Vonen (1989) A Handbook of the Tokelau Language. Oslo: Norwegian University Press/The Institute for Comparative Research in Human Culture, and Apia: Office for Tokelau Affairs.

Huang, C.T. James (1984) On the distribution and reference of empty pronouns. Linguistic Inquiny 15: $531-74$. 
Huntsman, J.W. (1969) Kin and coconuts on a Polynesian atoll: Socio-economic organisation of Nukunonu, Tokelau Islands. Unpublished PhD thesis, Bryn Mawr College, Pennsylvania.

Huntsman, J.W. (1971) Concepts of kinship and categories of kinsmen in the Tokelau Islands. Journal of the Polynesian Society 80: 317-54.

Levy, R.I. (1973) Tahitians: Mind and experience in the Society Islands. Chicago and London: University of Chicago Press.

MacGregor, G. (1937) Ethnology of Tokelau Islands. Honolulu, Hawaii: Bernice P. Bishop Museum Bulletin 146. Repr. New York: Kraus Reprint Co., 1971.

Mosel, U. and E. Hovdhaugen (1992) Samoan reference grammar. Oslo University Press/Oxford University Press.

Sallen, V.G. (1983) Tokelau scholars in New Zealand: Experiences and evaluations. Unpublished MA thesis, University of Auckland.

Senft, G. (1987) Rituelle Kommunikation auf den Trobriand Inseln. Zeitschrift für Literaturwissenschaft und Linguistik 65: 105-130.

Senft, G. (1991) Prolegomena to the pragmatics of 'situational-intentional' varieties in Kilivila language. In Jef Verschueren (ed.), Levels of Linguistic Adaption: Selected Papers from the 1987 Intemational Pragmatics Conference Vol. 11. Amsterdam: Benjamins, 235-248.

Shore, B. (1982) Sala'ilua: A Samoan mysten. New York: Columbia University Press.

TD = Tokelau Dictionany. Apia: Office for Tokelau Affairs, 1986

Vonen, A.M. (1988) The noun phrase in Samoan and Tokelauan. Unpublished Cand. Philol. thesis, University of Oslo. 